\title{
MeToo as connective action: a study of the anti-sexual violence and anti-sexual harassment campaign on Chinese social media in 2018
}

\author{
Zeng, Jing
}

\begin{abstract}
In January, 2018, the global anti-sexual violence and anti-sexual harassment movement - popularly known as MeToo - had its Chinese nascence. This study drew upon the theory of connective actions to investigate how digital technologies shift the way in which feminist activism takes place. Both quantitative and qualitative analyses were employed to systematically analyse over 36,000 online articles related to the campaign. The study identified 48 cases of sexual violence and harassment allegations. Findings from time series analysis show that China's MeToo campaign first emerged within educational institutions before gradually spreading to other sectors of society. Based on qualitative findings from the ten most controversial cases, this paper identifies a series of counter-censorship strategies. The study of how the MeToo movement in China emerged, adapted, and grew within an authoritarian context reveals unique insights into how connective actions traverse various platforms and cultural contexts. Methodologically, this study demonstrates how mixed methods can be utilised to study connective actions on social media in China.
\end{abstract}

DOI: https://doi.org/10.1080/17512786.2019.1706622

Posted at the Zurich Open Repository and Archive, University of Zurich ZORA URL: https://doi.org/10.5167/uzh-183939

Journal Article

Accepted Version

Originally published at:

Zeng, Jing (2020). MeToo as connective action: a study of the anti-sexual violence and anti-sexual harassment campaign on Chinese social media in 2018. Journalism Practice, 14(2):171-190.

DOI: https://doi.org/10.1080/17512786.2019.1706622 


\section{\#METOO AS CONNECTIVE ACTION}

\section{A study of the anti-sexual violence and anti-sexual harassment campaign on Chinese social media in 2018}

In January, 2018, the global anti-sexual violence and anti-sexual harassment movement - popularly known as \#MeToo - had its Chinese nascence. Placing emphasis on the socio-political and technological context of China, this study drew upon the theory of connective actions to investigate how digital technologies shift the way in which feminist activism takes place. Both quantitative and qualitative analyses were employed to systematically analyse over 36,000 online articles related to the campaign. The study identified 48 cases of sexual violence and harassment allegations. Findings from time series analysis show that China's \#MeToo campaign first emerged within educational institutions before gradually spreading to other sectors of society. Based on qualitative findings from the ten most controversial cases, this paper identifies a series of counter-censorship strategies that are summarised as 'cache' and 'camouflage'. The study of how the \#MeToo movement in China emerged, adapted, and grew within an authoritarian context reveals unique insights into how connective actions traverse various platforms and cultural contexts. Methodologically, this study demonstrates how mixed methods can be utilised to study connective actions on social media in China.

KEYWORDS connective actions; feminist activism; MeToo; social media; WeChat

\section{Introduction}

When sexual abuse allegations against Hollywood tycoon Harvey Weinstein and a number of other high profile men in the American entertainment industry surfaced in 2017, they triggered the \#MeToo campaign - a movement that soon mobilised around the world, including in China. On 1 January, 2018, inspired by \#MeToo, Luo Xixi, a former student of China's Beihang University, made an allegation on Chinese social media against her then supervisor - professor Chen Xiaowu. According to 
Luo's post, she was repeatedly harassed by Chen during her PhD studies. Her post received millions of views, and quickly led to Chen's sacking (Denyer \& Wang, 2018). This allegation marked the time when the \#MeToo movement took off in China. In the twelve months to follow, many more Chinese women, encouraged by the triumph of Luo's allegations, broke their silence and shared their own experiences of sexual abuse online.

China's participation in a worldwide anti-sexual violence and anti-sexual harassment movement presented a unique opportunity to research how a campaign that originated in a Western democracy could emerge, develop, and adapt within an authoritarian context. China's \#MeToo campaign has encountered challenges that are unique to its socio-political context. For example, the Chinese government rarely tolerates any form of collective action, regardless of its political nature (Fu, 2017; King et al., 2013). As the \#MeToo movement gained traction in China, the Chinese authorities were cautious and careful in their response. Broadly, both official media and government agencies acknowledged the importance of improving legislation and policies to ameliorate sexual violence and harassment in China (Kan, 2018). At the same time, measures were taken to contain the development of the online campaign. For instance, a number of hashtags related to \#MeToo were blocked, and the social media accounts of well-known feminist activists were strictly monitored, and some were even permanently suspended (Kuo, 2018; Zeng, 2019). In response to the online crackdown, social media users in China had to constantly adapt their strategies to sustain the online campaign.

Emphasising the socio-political and technological contexts of China, this paper draws upon the theory of connective actions (Bennett \& Segerberg, 2013) to 
investigate the interplay between social media and the \#MeToo movement in China. Alongside second-hand data from media reports and online archives, this study collected 35,872 articles published by WeChat public accounts in 2018 . WeChat is the most popular social media platform in China, with over one billion monthly active users (Xinhua, 2019). Alongside private users, WeChat hosts another 12 million 'public accounts' managed by authenticated individuals and organisations. These accounts can publish available articles on the platform. As indicated in prior studies (e.g. Yi \& Cheng, 2015; Zhao, 2014), WeChat's public accounts now serve as a key source of news and information for Chinese internet users. The current study employs both quantitative and qualitative methods to examine (1) how various \#MeToo allegations unfolded on WeChat, and (2) what strategies were used to bypass online censorship.

This empirical study of the interplay between social media and the \#MeToo campaign in China contributes to the growing body of literature on global \#MeToo movements. By operationalising the connective actions theory through mixed method analyses of social media data, this study also contributes to the broader scholarship of online activism with its theoretical and methodological foci. Additionally, the Chinese perspective on how the global anti-sexual violence and anti-sexual harassment emerged, adapted, and grew within an authoritarian context reveals unique insights into how feminist activism traverses various platforms and cultural contexts.

\section{Literature Review}

\subsection{Feminist activism in China}

From the crusade against foot binding during the 1919 May Fourth Movement (Li, 2012), to the emancipation of the female labour force under Mao's leadership, 
women's liberation is an indispensable part of China's trajectory toward modernisation. In recent years the Chinese Communist Party (CCP) has further advanced laws and policies to assert women's equal rights in the country (Yi et al., 2009). However, the lived reality for women in China is still one of entrenched gender disparities. In Hsiung \& Wong's (1998) words, 'a by-product of such a topdown approach to women's liberation is that although Chinese women are formally entitled to legal rights, in real life these rights are often compromised'.

The gap between official legislation and the social reality of women's lives is well exemplified by the issue of sexual harassment, which is still a prevalent issue in Chinese society (Pan \& Huang, 2013). Patriarchal forms of authority, and the social acceptance of women's subordination in China, foster sexual violence against them (Liu, 1999; Xu et al. 2005). In the 2000s, in an attempt to improve existing laws that protect women, a number of provinces in China passed new bills outlining the specific definition of 'sexual harassment' (Huang, 2010). Nevertheless, the new legislation did little to encourage women to speak out and seek help (China Daily, 2010). This reluctance, to a large extent, stemmed from traditional gender norms and cultural values. As shown in Dussich's study (2001), the Buddhist teaching that one must endure one's plight in life, as well as the Confucian ethics of deferring to persons of greater status (that is, those who are older or those in authority), contributed significantly to the under-reporting of sexual violence in East Asia.

The disparity between top-down legislation and women's real experience, as demonstrated in the case of sexual harassment, fostered the emergence of bottomup initiatives in China. For instance, in the 1990s, China's 'opening up', and its resulting economic reforms, catalysed the first generation of bottom-up feminism ( $\mathrm{Li}$ 
\& Li, 2017). The second wave emerged in the 2010s, and coincided with China's social media boom. China's feminist movement in the 1990s was organised predominantly by women's rights' NGOs, which relied on their close ties to the government to accomplish their aims (Wang, 2018). In contrast, the younger generation of feminists are more grassroots, and are not affiliated with established organisations (Li \& Li, 2017; Tan, 2017).

As Wang (2018) points out, while the first generation to grow up under the postsocialist market economy, China's young feminist activists are more self-assertive, more ready to challenge the status quo, and are better connected to the outside world than their predecessors were. Moreover, whereas China's feminist activism in the 1990s took a critical and cautious approach to incorporating Western feminist ideas into local gender politics (Hsiung \& Wong, 1998), the new feminists are more ready to incorporate international feminist agendas. It is worth pointing out, that participation in the \#MeToo movement is not the first time that Chinese feminists have attempted to be part of a transnational campaign. In 2012, inspired by Occupy Wall Street, they occupied male public toilets in various cities as a protest against the shortage of female toilets (Jacobs, 2016). In 2013, university students from China introduced their own version of global V-day campaign, a global anti-sexual violence campaign inspired by Eve Ensler's Vagina Monologue (Huang, 2016). Another characteristic of the younger generation of feminist activists in China is their media savviness. As demonstrated in prior studies of feminist activism, these young feminists deploy sophisticated strategies to cultivate alliances with mainstream journalists, while at the same time mobilising public support through social media (Han, 2018; Li \& Li, 2017). For instance, earlier studies have documented how 
feminist activists in China deploy hashtag campaigns to reach both public and media attention (Wang \& Driscoll, 2019; Zeng, forthcoming). While their Western counterparts often use social media campaigns to supplement offline demonstrations, Chinese feminists have a much larger dependence on social media to promulgate their causes. This is because demonstrations and protests are rarely allowed by the government.

While social media has provided more room for feminists to be heard in China, it has not shielded feminist activism from government intervention and crackdowns.

Because of its detachment from state-sanctioned channels, grassroots feminism in China has always struggled to obtain legitimacy. From removing feminist content to shutting down activists' social media accounts (Fincher, 2016), the Chinese government routinely attempts to contain online feminist activism (and other forms of activism) to quash any form of collective action (King, 2013). In order to survive this form of 'state-sanctioned misogyny' (Han, 2019), feminists in China are forced to incorporate contingency and resilience in their media strategies.

In summary, China's contemporary feminists have emerged in an environment where there are still tensions between modernisation and millennia-old traditional gender norms; between an emerging sense of individualism and the authoritarian rule of the one party State; and between a history of non-advocacy for women and their empowerment by new information and communication technologies. This paper explains the significance of the \#MeToo campaign within China's feminist movement, and its connections with the broader phenomenon of online activism. The following section introduces the theoretical framework of connective actions, and how it can serve as a suitable theoretical lens for this study. 


\subsection{Connective actions}

To understand the interplay between digital media and social movements, including feminist movements, various theoretical approaches to capture the new dynamics of organising and participating in collective actions in online environments have been proposed. From the early 2000s, a number of scholars have focused on how new information and communication technologies (ICTs) can help to facilitate offline political engagement and collective action by mobilising resources and expanding the scale of the movements (e.g. Aelst \& Walgrave, 2002; Nip, 2004; Kavada, 2005).

While it does focus on investigating the potential of new ICTs for organising collective actions, most of this early work follows conventional social movement theories (e.g. Olson, 1965; McCarthy \& Zald, 1977); that is, by depicting formal social movement organizations (SMOs) as the centre of social movements, and technologies as instrumental tools.

More recently, however, a growing number of scholars have moved away from this assumption, and have contextualized social movements in the digital environment by focusing on the structural change brought about by new technologies (Bimber, 2016). As Earl and Kimport (2011, p. 29) suggest, digital media 'does not just supersize activism, it can change how it takes place'. Bennett and Segerberg's (2013) work concretely outlines how digital media can foster distinctive forms of collective action, and coined the term 'connective actions' to describe the latter.

At the core of Bennett and Segerberg's (2013) concept of connective actions, is the recognition of digital media as organizing agents. Unlike the aforementioned technology-as-instrument approach in traditional collective action theories, the theoretical framework of connective actions takes a technology-as-context approach 
(Bimber, 2016), and highlights the fact that new communications platforms can subsume conventional SMOs and constitute organisations in their own right (Bennett and Segerberg, 2013). One related concept is Chadwick's (2017) hybrid media logics, which suggests that the genres, norms, behaviours, and organizational forms of media platforms can penetrate various social fields and shape political activities. For example, earlier studies on the Arab Spring and the Occupy movement around the world, as well as many other case studies, have documented numerous circumstances wherein media, both traditional and new, were deployed together to effectively mobilize, support, and coordinate activities (e.g. Lim, 2013; Kavada, 2015; Zheng \& Yu, 2016 ).

In comparison to conventional SMOs, the organisational power of new digital technology has a unique flexibility to frame and cooperate. First, most digital mediaorganised movements depend on a loose coalition between individual participants. This allows individuals to engage with the issue on their own terms by adopting easily personalisable action frames. To put it in Bennett and Segerberg's (2013) words, under the connective actions logic, the networks of actions are 'dense with pathways for individual networks to converge, enabling viral transmission of personally appealing action frames to occur' (p. 761). Second, cooperation between these loosely connected individuals can be 'spontaneous, and supple, and continually adapted and readopted according to the goals being pursued' (Chadwick, 2017, p. 22).

One concrete example of digital media's flexible organisational capacity is its use of hashtags. The practice of using hashtags to draw attention to, and to organise connective actions is also described as 'hashtag activism' (Clark, 2016; Williams, 
2015; Yang, 2016). From \#BlackLivesMatter to \#MeToo, hashtags now function as organising agents in various discursive protests online. Because hashtags are highly personalisable and localisable, they can constantly evolve and adapt as connective actions expand. Hence, hashtags can be considered as what Bennett and Segerberg theorise as 'representative symbols of personalised action frames' (Pond \& Lewis, 2017, p. 217). Likewise, Papacharissi (2016) describes the hashtags used in online connective actions as signifiers that are 'open to definition, redefinition, and reappropriation' (p. 308).

Bennett and Segerberg's (2013) theory of connective actions has its limitations, however. For example, both Karpf (2014) and Kavada (2015) point out that this theory overlooks the significance of core members who denote deep, time-intensive participation. Other critics of the theory (e.g. Condes \& Schucher, 2013; Lim, 2013; Morozov, 2011) suggest that what Bennett and Segerberg (2013) describe as 'connective actions' are often short-lived, unsustainable, and have limited influence on offline events. Although these are valid criticisms, how activism can, or should be effectively organised is contextually specific. The logic of connective actions, therefore, is considered a suitable theoretical lens through which to study feminist activism in an authoritarian state such as China.

First of all, given China's particular socio-political environment, feminist activism can rarely develop into large-scale coercive collective actions. Like other oppressive political systems, where conventional SMOs are tightly restricted or non-existent and where mass media is tightly controlled, activism relies on unique action tactics and requires constant negotiation (Yang, 2009; Zeng et al., 2017). In this context, new 
communication technologies serve as a critical, and sometimes sole, conduit through which activists can organise both online and offline activities (Zhou, 2009).

Moreover, for feminist activism to survive in a repressive environment, flexible action frames are critical. In the case of China, such flexibility is related to resilience and sustainability, because a unified and coercive action frame is an easy target for a party-state's suppression. For this reason, most online activism in China is fragmented and in a state of constant adaptation (Sima, 2011; Zeng, 2019). For instance, activists in China often need to adopt various communication strategies to evade censorship. A variety of these strategies are documented in prior research of social media in China. For example, in her study of journalistic practice, Xu (2015) outlines strategies employed by Chinese journalists to bypass online censorship; these include the use of homophones to replace sensitive words, and the deverifying of social media profiles to disguise identity. Mina (2014) and Yang (2016) also highlight the efficacy of using memes, such as humorous puns and visual images, to express political criticism and dissent under the suppressive Chinese media system.

Considering the factors discussed above, conventional approaches to theorising collective actions have their limitations in capturing the ad-hoc and spontaneous characteristics of feminist activism in China. Using connective actions as the theoretical lens, this study examined how various anti-sexual violence allegations were communicated online during the \#MeToo campaign. To this end, the following question was asked:

RQ1: How did various \#MeToo allegations unfold on WeChat? 
The use of creative tactics to counteract censorship is a significant component of a civic culture, and sustains online connective actions in China (Meng, 2011; Yang, 2014). As previously mentioned, feminist activism has long been a target of the Chinese authorities' online crackdown (Wang \& Driscoll, 2019), and \#MeToo campaigns have also encountered harsh censorship since \#MeToo's launch in China in 2018. Therefore, this study also examined how activists interplay with censorship; thus, the following question was posed:

RQ2: How are various strategies used to bypass online censorship?

\section{Methods}

\subsection{Data collection}

As mentioned earlier, the Chinese \#MeToo campaign began on 1 January 2018, when Luo Xixi made her open allegation. For this reason, this study set this date as the starting point for data collection, and its end point was set at 31 December, 2018. This timeframe allowed the study enough data to cover the development of \#MeToo in China throughout 2018. Because WeChat does not have application programming interfaces (APIs), web-crawlers are commonly used to collect data for academic research accounts (Fu, 2018). For this study, therefore, a web-crawler was developed to retrieve WeChat articles from a third party search engine - Sogou (sogou.com) - where historical WeChat posts from public accounts are archived. The crawler visited and sent the search query '性骚扰' and '性侵' ('sexual harassment' and 'sexual assault') to Sogou. Moreover, using the search engine's time filter function, the crawler collected up to $100^{1}$ articles that were most relevant to the

\footnotetext{
${ }^{1}$ Sogou's search results are mostly ranked by relevance. Therefore, to minimize the amount of 'false positive' data collected, I set 100 as the upper limit. Also, to access to more than 100 results for each
} 
search term from each day of the timeframe. In total, 35,872 WeChat articles were collected.

It is worth noting that not all articles in the dataset are related to the \#MeToo movement in China, so more specific keywords (such as names of individuals involved in a reported \#MeToo incident) were used to select content related to individual cases. To develop a robust list of all reported \#MeToo cases in China, this study also collected second hand data from media reports in both established news outlets and online archives. Online \#MeToo campaign archives were established to aggregate activists and journalists' reports related to \#MeToo in China. The same time frame (1 January-31 December, 2018) was used to collect these media articles. In total, 125 articles were collected manually.

\subsection{Analysis}

This study employed mixed methods; that is, quantitative and qualitative approaches were both used to answer the two research questions. To begin with, the study used a two-step analysis procedure to explore how various allegations unfolded on WeChat (RQ1). As the first step, a qualitative documentation analysis of media reports was conducted to develop a list of reported \#MeToo allegations. In total, 62 cases were identified. Based on these cases, to identify related content from the WeChat dataset, the author developed a list of keywords, such as names of the individuals involved in each allegation. From the WeChat dataset, articles specifically related to each of 48 individual cases of sexual abuse allegations were separately selected. 
In the second step of the analysis, each of these subsets of WeChat data was used for time-series and sentiment analysis. The National Taiwan University Semantic Dictionary (NTUSD) was used to conduct a sentiment analysis of the articles collected. Two sentiment metrics were calculated for each article: positive sentiment ratio, and negative sentiment ratio. Positive sentiment ratio is calculated by dividing the number of positive words by the number of morphemes extracted from the tokenized version of an article; meanwhile, negative sentiment ratio is calculated by dividing the number of negative words by the number of morphemes.

The rationale for the use of sentiment analysis was the need to gain a general understanding of the public's emotional response to various \#MeToo stories. Emotion is an important aspect of connective actions, as it sparks the motivation to participate in such action (Van Zomeren \& Lyer, 2009). For decades, in both theoretical and empirical studies, scholars have identified anger as an 'actionoriented emotion' (Mackie et al., 2000; Montada \& Schneider, 1989) - a key predictor of individuals' participation and support for collective action (Lyer et al., 2007; Van Zomeren et al., 2004). Therefore, the emotion measure assisted the study's interpretation of the time series and qualitative findings. This interpretation, in turn, helped to build a more complete picture of the emergence and development of the \#MeToo campaign.

To study the anti-censorship strategies used in \#MeToo (RQ2), the ten most controversial cases were selected for qualitative analysis. Two quantitative measures were used to select these ten cases: prevalence and outrage. The former was measured by the number of related articles in the WeChat dataset, and the latter by the level of negative sentiment expressed in these articles. As shown in the 
relevant literature, popular and outrageous content is also more prone to censorship (King et al., 2013; Fu et al., 2013). Therefore, a focus on these ten cases was more likely to provide anti-censorship content.

The selected cases are presented in Figure 1. To interrogate how various strategies were used to bypass online censorship, an in-depth qualitative analysis of media content and WeChat posts related to the ten cases, was conducted.

[insert Figure 1 here]

\section{Findings}

\subsection{Campaign development}

From the WeChat dataset, 48 cases of sexual abuse allegations were identified. These cases emerged from four social sectors: education $(N=27)$; media $(N=10)$; civil society $(\mathrm{N}=7)$; and the business sector $(\mathrm{N}=4)$. The stacked area graph in Figure 2 shows the percentage of articles related to \#MeToo allegations from these four sectors (Figure 1). Figure 2 also shows the positive and negative sentiment ratios for articles related to the cases from each sector.

[Insert Figure 2 here]

[Insert Figure 3 here]

\section{Education sector}

As the time series analysis shows, throughout the first seven months of 2018, \#MeToo stories in China almost exclusively came from educational institutions. During this time, over 20 allegations against university professors in China were made by current and former graduate students. 
As discussed in Zeng (2019), the reason why universities became the staging grounds for China's \#MeToo movement is related to the power structures in Chinese educational institutions and the international network of graduate students in China. China has a long tradition of valuing education, and students are expected to have total respect and obedience in all circumstances (Bush \& Qiang, 2000). This power imbalance, together with documented corruption in the Chinese education system (Yang, 2015), makes Chinese universities more prone to abuse. Another factor driving the proliferation of \#MeToo in Chinese universities is the increasingly internationalised network of graduate students and alumni. The vast number of Chinese students living overseas (MOE, 2018) - especially those in North America may be among the first Chinese citizens exposed to \#MeToo movements. Some of these individuals made a crucial contribution to the evolution of \#MeToo in their home country. For example, a number of the pioneers of the \#MeToo campaign on Chinese social media (including Luo Xixi) were students based in the US and Canada (Denyer and Wang, 2018).

In the wake of the series of allegations of sexual abuse on campuses, both the Ministry of Education and individual universities agreed to develop anti-sexual harassment mechanisms to protect students (Zhou and Zheng, 2018). Positive reports of government officials' response to university activists contributed to the positive emotion captured in the sentiment analysis. As shown in Figure 2, in terms of positive sentiment, cases against university professors scored the highest. As suggested by the qualitative analysis of the sampled articles, articles with the highest positive sentiment ratio were mostly those that discussed these progressive policy changes. 


\title{
Civil Society
}

In the second stage of the campaign in China - June 2018 onwards - \#MeToo spread to the civil society sector. By the end of 2018 , seven well-known personalities in Chinese NGOs were accused of sexual harassment or sexual assault. Accused individuals included leaders of prominent NGOs, and a high profile Buddhist monk. As in the case of allegations made by university students, sexual violence allegations against these individuals were made on social media by women who were formerly employed by, or worked with them.

The highest level of outrage (measured by negative sentiment) was observed in articles related to these sexual abuse allegations in civil society organisations (mean negative ratio $=0.0758$ ). Qualitative readings of sample articles from this group show that the controversies around them were particularly inflammatory. This high level of negative sentiment is not surprising as these individuals were supposedly moral exemplars in Chinese society. As the public account @Gongyiwangxi wrote in her WeChat article:

\begin{abstract}
Public welfare organisations are supposed to be the purest and cleanest field. The recent dirty and despicable scandals make the public start to reflect: some so-called public welfare organizations are nothing more than self-interested gangs... It's time to tear open the aura of these charity celebrities and reveal their ferocious faces! Let's make these scums understand: without personal morality, there is no place for them to work on public welfare! [See Figure 4, translated by author]
\end{abstract}

[Insert Figure 4 here]

\section{Media industry}

During the same period when allegations from civilian society emerged, ten individuals from media industries were also accused of sexual assault. Among those accused was a high-profile host of China's Central Television (CCTV) - Zhu Jun. As 
one of the most prominent CCTV presenters, Zhu had been long regarded as a respected public figure. In August 2018, Xuanzi - a former intern of CCTV - shared on social media that she was sexually assaulted by Zhu when she worked with him. Because Zhu was one of the most prominent presenters of the state broadcaster, this allegation against him was highly controversial and sensitive. As is further discussed below, Xuanzi's efforts to share her story were met with stringent censorship.

\section{Business Sector}

In the business sector, there were four identified \#MeToo cases from the WeChat dataset. The most widely discussed case from this category was an allegation against Liu Qiangdong, an e-commerce tycoon. Over 700 articles related to this case were found. The initial allegation was made by a Chinese college student at the University of Minnesota, who filed a lawsuit in the US accusing Liu of rape. The allegation went public in China around September 2018, in the midst of the country's \#MeToo movement. Therefore, it was discussed in conjunction with many other \#MeToo stories that were breaking or developing in China. This case also received widespread attention because both Liu and his wife were well known public figures in China.

In comparison with previous feminist movements in China, the currently study demonstrates that the development of the \#MeToo campaign had its own distinctive characteristics. To begin with, it is Chinese grassroots activists' first direct participation in a global social media-initiated feminist movement. Since its earliest identification with the international feminist movement in the mid-1990s, Chinese feminists' fight for equality has been a constant negotiation between global and local 
activism (Hsiung \& Wang, 1998). Previous studies have reported that Chinese activists' attempts to introduce 'Western' feminist campaigns have been labelled as 'uncritical imitations of Western culture'; therefore, they are more vulnerable to government intervention (Huang, 2016; Tan, 2017). Hence, it can be particularly challenging for a movement with a foreign origin, such as \#MeToo, to take root in China.

The reasons why \#MeToo successfully flourished in China are complex. Apart from the technological reasons discussed previously, the anti-sexual harassment nature of the campaign, and the growing international network of Chinese feminists were two important factors. First, as previously discussed, sexual abuse and assault was a prevalent issue in Chinese society. For many Chinese women, the \#MeToo campaign provided an outlet for them to tell their personal stories. Xuanzi, the woman who openly accused CCTV host Zhu Jun of sexually assaulting her, made the following statement in an interview published on WeChat:

I now realise how the \#MeToo movement develops and expands: It does not rely on men, but on women who quickly build solidarity. If you are a women, and if you grew up in this environment, everyone's body will hold some kind of memory (of sexual abuse), of which you can never be rid. Other women have empathy toward me, because our bodies have shared memory. My mother can understand my story, not because I am her daughter, but because she is also a woman and she has had similar experiences. (cited in Zeng, 2019)

This quote summarises how an ad-hoc bond among women participating in \#MeToo emerged as the result of their shared experiences and mutual empathy. In this context, emotion aroused, motivated, and channelled women's energy to fight for others, and for themselves.

Second, as findings from this study show, the Chinese diaspora - especially those based in North America - have played an indispensable role in introducing \#MeToo 
to China. They effectively utilised Chinese digital platforms to export and localise the campaign to their home country. Because almost all major international social media sites are blocked in China, the diaspora plays a significant role as 'brokers,' connecting the global \#MeToo movement to the home campaign. The Chinese \#MeToo campaign's affiliation with the broader international movement further encourages activists in the country by demonstrating that they are not isolated in their struggle.

\subsection{Counter-censorship}

Because the maintenance of 'social stability' is a top priority of the Chinese partystate, gatherings and protest demonstrations are strictly forbidden, and online collective actions are also considered to be destabilising threats (Cai, 2008; Weber, 2011). As a number of researchers point out (Fu, 2017; King et al., 2013; Zheng \& Wu, 2005) online activism, which can potentially lead to large-scale collective action, has long been a major target of the Chinese authorities' censorship. Against this socio-political backdrop, it is not surprising that Chinese authorities have cracked down on a number of outrageous \#MeToo stories (Kuo, 2018; Zeng, 2019).

In order to study the counter-censorship social media tactics used by China's \#MeToo supporters, ten of the most prevalent and inflammatory cases were chosen for in-depth qualitative analysis (Details of the case selection were earlier discussed in the method section). Strategies identified in the study are termed cache and camouflage.

Cache describes the anti-censorship practice of restoring and hiding previously deleted content in platforms that are less likely to be targeted by Chinese censors. The allegation against Shen Yang, a professor at Beijing University, best illustrates 
this tactic. Following the emergence of the \#MeToo movement in Chinese universities, a group of students from Peking University (PKU) distributed a petition demanding that university officials reopen the investigation of a case dating back to 1998. The case involved a female student who committed suicide after making sexual assault allegations against her professor, Shen Yang. The petition was rejected by PKU authorities; however, one of the petition's authors, Yue Xin, published an online letter revealing how she was pressured and threatened by university officials to withdraw the petition (Hernández, 2018). This letter was shared widely before it was erased on all Chinese social media platforms a couple of days later by censors acting at the behest of authorities (Zeng, 2019).

Supporters of Yue Xin devised innovative strategies to restore the letter to locations that were safe from censors; for example, by caching sensitive content on blockchain and GitHub. In April 2018, an unidentified Yue supporter made an empty transaction to him or herself on Ether, a cryptocurrency. This user attached Yue's open letter to the transaction record, in order to permanently cache it within the tamper-proof blockchain Ether system. To this day, anyone can access this transaction record and read Yue's letter (See the URL displayed in Figure 5).

[Insert Figure 5 here]

Likewise, a number of users of GitHub - a platform used mostly by programmers to share and manage code - uploaded Yue's letter to the site (see Figure 6). Because GitHub is located and operated outside China, it is relatively immune from Chinese censorship. Moreover, as it is a valuable resource for Chinese IT developers, it has not been blocked in China. At the time of writing, GitHub remains - at least for now a safe space to cache sensitive material from censorship. 
[Insert Figure 6 here]

Camouflage, on the other hand, refers to tactics used to circumvent content censorship through content modification. One of the most common examples of camouflage tactics is the use of homophones. Because keyword blocking is frequently used by Chinese authorities to censor sensitive content, Chinese internet users have developed a rich culture of adapting sensitive keywords into homophones. As discussed above, such a practice has a long history, and has been widely documented in prior research (Meng, 2011; Mina, 2014; Nordin \& Richaud, 2014).

The use of camouflaging to modify sensitive keywords was also observed in the data in the case of the \#MeToo campaign. In the wake of numerous online allegations, the \#MeTooMovementInChina hashtag was censored on social media (Zeng, 2019; Lim, 2018). As an attempt to circumvent the crackdown, social media users launched an alternative hashtag: \#rice bunny in China, \# (米兔在中国). 'Rice bunny' is phonetically pronounced 'mi tu' in Chinese; thus, it was employed as the coded name for 'me too'. For the same reason, as shown in Figure 7, the paired emoji of a bowl of rice and a rabbit have also become a symbol of the campaign in China.

[Insert Figure 7 here]

Alongside homophones and emoji, foreign languages and local dialects have also been employed as 'coded language' for camouflaging \#MeToo. For instance, on WeChat, '\#老子也是\# and \#俺也一样\# - meaning 'me too' in Sichuan and Northern Chinese dialects respectively - were both used in collected articles. Another interesting adaptation of the \#MeToo hashtag is \#a'metoo'fo\#, a play on 'amituofo' a 
greeting common among Chinese Buddhist monks. This hashtag became popular after the scandal of the high profile Buddhist monk Shi Xuecheng came to light. Both examples are presented below (Figure 8).

[Insert Figure 8 here]

Similarly, during China's \#MeToo campaign, one of the accused predators, highprofile CCTV presenter Zhu Jun, was referred to online as 'swine bacteria' (zhu jun,

( ), which has a similar pronunciation to his name. Because of his 'official background', posts concerning the allegations against him were often censored. For this reason, Chinese netizens referred to him as 'swine bacteria' to bypass the censorship and share information about the allegations.

Text is not the only target of censorship, however. Occasionally, sensitive images related to China's \#MeToo campaign were also 'camouflaged' to avoid censorship. In general, it is technically more challenging to detect texts embedded in an image, than it is to detect plain text posts. For this reason, it is a common practice on Chinese social media to post pictures to evade censors. However, as text-detection algorithms have become more sophisticated, social media platforms in China can increasingly detect text embedded in images. Consequently, more innovative methods were used to camouflage images during the \#MeToo campaign in China.

For example, to trick image detection algorithms, social media users rotated images when posting them online. Figure 9 displays two examples of rotated images from the WeChat dataset. In the first example, an article about the allegations against Zhu Jun was deliberately posted upside down, following the message '\#swine bacteria\#. 
In the second picture, the letter from Yue Xin was posted slightly rotated. It included the poster's message:

In the last few days social media has been flooded with posts related to Yue Xin, especially her open letter, which was constantly censored, but continuously reposted using various methods. The tilted text below is an example.

[Insert Figure 9 here]

As introduced in Section 2, connective actions encourage flexible and personalised frames of action, because they contribute to the maintenance and reach of the movement. In the current study of \#MeToo in China, the clearest manifestation of flexible and personalised action frames is the campaign supporters' anti-censorship tactics. To keep \#MeToo alive, individuals introduced their own pathways to contribute to the campaign through modifying and passing on sensitive material to resist censorship. However, because the resistance is highly decentralized, spontaneous, and constantly evolving, it is difficult to censor effectively.

Chinese netizens' duel with censorship is a conjunction of political and cultural responses (Meng, 2011; Yang, 2016). This is because their attempts to evade censors are driven by political frustrations, as well as by an internalised demand for collective meaning making. The repressive internet environment has fostered a generation of internet users who enjoy a rich culture of using coded language, puns, and sarcasm to express their ideas, and who come together to support one another on controversial issues (Yang, 2014). As seen from the example of \#MeToo supporters' efforts to cache and camouflage sensitive material, their creative tactics integrate elements of popular internet culture, such as memes, humour, and satire. These individuals participate in crowd-sourced efforts to keep censored material accessible to the connective community, where self-identification as an 'activist' and 
the formation of a united 'we' are obsolete (Bondes \& Schucher, 2014). In the context of China, such adaptability is the key to the survival of any connective action.

\section{Conclusion}

This paper provides insights into China's home-grown \#MeToo movement, with particular emphasises on the technological and geopolitical context of the country. It employs connective actions logics (Bennett \& Segerberg, 2012), focusing on how digital technologies shift the way in which feminist activism takes place as an organising actor, rather than as a mere instrumental tool. Utilising results from qualitative and quantitative analyses of WeChat posts and media reports, the study illustrates how \#MeToo emerged in China's higher education institutions, and gradually expanded to the media industry, civil society, and the business sector.

This study also shed light on how online censorship is evaded by \#MeToo supporters in China. Like many other online campaigns, \#MeToo encountered stringent online censorship. However, netizens' ensuing response demonstrated a crucial aspect of connective actions in the Chinese digital environment. Qualitative findings demonstrate the creative counter-censorship strategies used during the campaign to circulate sensitive materials. These included the use of blockchain technologies, image modification, and coded language with playful puns. Although \#MeToo supporters' social media strategies echo the tactics of previous Chinese internet dissidents (Mina, 2014; Yang, 2016), the current study has shown that the technological barriers are becoming increasingly challenging for both censors and activists. 
The development of China's \#MeToo campaign discussed in this paper epitomises the dynamics of China's grassroots feminist movement. According to earlier literature, in comparison to China's first generation of feminists, younger feminist activists are characterised by their openness to Western feminist ideas and their digital media-savviness (Wang, 2018; Tan, 2017). Both points are further supported by the findings of this study.

As mentioned earlier, the Chinese grassroots activists' \#MeToo campaign is their first direct participation in a global social media-initiated feminist movement. Although the \#MeToo movement originated in the US, sensitivities around the topic of sexual harassment brought to the fore by the movement succeeded in arousing widespread outrage and in inciting active discussion within Chinese society. In this process, the Chinese diaspora played a crucial role in introducing the campaign to their home country. Furthermore, to maintain the campaign in China's repressive online environment, collaborative efforts were made to constantly adapt \#MeToo's communication strategies. These efforts were exemplified by the creative tactics used by \#MeToo activists to alter images and hashtags. This form of crowd-sourced resistance was a key factor in contributing to the sustainability of the movement.

One major limitation of China's \#MeToo campaign was that it did not reach more marginalized groups. The problem of 'inclusion' and 'diversity' has become a common critique of the global \#MeToo movement (Kagal, Cowan \& Jawad, 2019; Ison, 2019), and China is no exception. Low-income workers and youths living in rural areas in China, for instance, are particularly vulnerable to sexually violent crimes, but they still struggle to be heard. As Zeng (2019) points out, because a certain amount of 'social capital' is still required to be considered a credible and 
media-worthy victim, the individuals involved in China's \#MeToo campaign are almost exclusively well-educated and media-savvy 'elites'. Due to the widening social disparities in China, meaningful change in gender politics requires more 'elite women' to grow their fight for women's rights so that it reaches a wider social sphere.

Consistent with findings from earlier research on activism in China, the \#MeToo campaign appeared to be fragmented. Although allegations against sexual violence emerged from a variety of social sectors, there was no cohesive force to mobilise China's \#MeToo campaign into a broader collective action. If the global \#MeToo movement is a large-scale war against sexual abuse (with Twitter being the main battleground), China's \#MeToo movement is a fragmented guerrilla campaign. However, although researchers frequently claim that fragmentation undermines the efficacy of collective actions (e.g. Jacobsson, 2012; Onuch, 2015), this study argues that it can contribute to its resilience and sustainability. This is especially true of the feminist movement in China and other authoritarian states. Because the party state has little tolerance of large-scale collective actions, the organising of a cohesive social movement inevitably attracts a thorough crackdown. In this environment, the more sustainable strategy for feminist campaigns is to keep the action frame adaptable, and to make the distributed core unlocatable. While this disorderliness may lack momentum and efficiency on the surface, it accrues strength and meaning over time. As Papacharissi (2016, p.321) states:

Change is gradual. Revolutions may spark instantaneously, but their impact is not instant; it unfolds over time, and for good reason. Revolutions are meaningless unless they are long. They have to be long to acquire meaning.

\section{REFERENCES}


Bimber, B. (2017). Three prompts for collective action in the context of digital media. Political Communication, 34(1), 6-20.

Bondes, M., \& Schucher, G. (2014). Derailed emotions: The transformation of claims and targets during the Wenzhou online incident. Information, Communication \& Society, 17(1), 45-65.

Bush, T., \& Qiang, H. (2000). Leadership and culture in Chinese education. Asia Pacific Journal of Education, 20(2), 58-67.

Cai, Y. (2008). Social conflicts and modes of action in China. The China Journal, (59), 89-109.

Chadwick, A. (2017). The hybrid media system: Politics and power. New York: Oxford University Press.

China Daily (2010, May 28). Law lists specifics of sexual harassment. Available at www.china.org.cn/china/2010-05/28/content_20133502.htm

Clark, R. (2016). "Hope in a hashtag": the discursive activism of\# WhylStayed. Feminist Media Studies, 16(5), 788-804.

Denyer, S. and Wang, A. Z. (2018, January 9). Chinese women reveal sexual harassment, but \#MeToo movement struggles for air. The Washington Post. Available at: https://www.washingtonpost.com/world/asia_pacific/chinesewomen-reveal-sexual-harassment-but-metoo-movement-struggles-forair/2018/01/08/ac591c26-cc0d-4d5a-b2ca-d14a7f763fe0_story.html

Dussich, J. P. (2001). Decisions not to report sexual assault: A comparative study among women living in Japan who are Japanese, Korean, Chinese, and English-speaking. International Journal of Offender Therapy and Comparative Criminology, 45(3), 278-301.

Earl, J., \& Kimport, K. (2011). Digitally enabled social change: Activism in the internet age. Cambridge: Mit Press.

Fincher, L. H. (2016). China's Feminist Five. Dissent, 63(4), 84-90.

Fu, D. (2017). Disguised collective action in China. Comparative Political Studies, 50(4), 499-527.

Fu, K. W., Chan, C. H., \& Chau, M. (2013). Assessing censorship on microblogs in China: Discriminatory keyword analysis and the real-name registration policy. IEEE Internet Computing, 17(3), 42-50.

Han, X. (2018). Searching for an online space for feminism? The Chinese feminist group Gender Watch Women's Voice and its changing approaches to online misogyny. Feminist Media Studies, 18(4), 734-749. 
Han, X. (2018). Searching for an online space for feminism? The Chinese feminist group Gender Watch Women's Voice and its changing approaches to online misogyny. Feminist Media Studies, 18(4), 734-749.

Hernández, J. C. (2018, April 9). China's \#MeToo: How a 20-Year-Old Rape Case Became a Rallying Cry. The New York Times. Available at https://www.nytimes.com/2018/04/09/world/asia/china-metoo-gao-yan.html

Hsiung, P. C., \& Wong, Y. L. R. (1998). Jie Gui-connecting the tracks: Chinese women's activism surrounding the 1995 World Conference on Women in Beijing. Gender \& History, 10(3), 470-497.

Huang, R. (2010, May 27) Guangzhou mingque xingsaorao dingyi jianyi duoyong kaifangshi bangongshi. In Guangzhou Daily. Available at http://news.ifeng.com/mainland/detail_2010_05/27/1557462_0.shtml

Huang, Y. (2016). War on women: interlocking conflicts within The Vagina Monologues in China. Asian journal of communication, 26(5), 466-484.

Huang, Y., Pan, S., Peng, T. \& Guo, Y. (2009). Teaching sexualities at Chinese universities: context, experience, and challenges. International Journal of Sexual Health, 21(4), 282-295.

Ison, J. (2019). 'It's Not Just Men and Women': LGBTQIA People and\# MeToo. In Fileborn B., Loney-Howes R. (eds) \# MeToo and the Politics of Social Change (pp. 151-167). Palgrave Macmillan, Cham.

lyer, A., Schmader, T., \& Lickel, B. (2007). Why individuals protest the perceived transgressions of their country: The role of anger, shame, and guilt. Personality and Social Psychology Bulletin, 33(4), 572-587.

Jacobs, K. (2016). Disorderly conduct: Feminist nudity in Chinese protest movements. Sexualities, 19(7), 819-835.

Jacobsson, K. (2012). Fragmentation of the collective action space: The animal rights movement in Poland. East European Politics, 28(4), 353-370.

Kagal, N., Cowan, L., \& Jawad, H. (2019). Beyond the Bright Lights: Are Minoritized Women Outside the Spotlight Able to Say\# MeToo? In Fileborn B., LoneyHowes R. (eds) \# MeToo and the Politics of Social Change (pp. 133-149). Palgrave Macmillan, Cham.

Kan, F. (2018, January 16). Jiaoyubu Zaidu Huiying Xiaoyuan Xingsaorao. China News. Available at www.chinanews.com/gn/2018/01-16/8425137.shtml

Karpf, D. (2014). Comment on 'Organization in the Crowd: peer production in largescale networked protests'. Information, Communication \& Society, 17(2), 261263. 
Kavada, A. (2015). Creating the collective: social media, the Occupy Movement and its constitution as a collective actor. Information, Communication \& Society, 18(8), 872-886.

King, G., Pan, J., \& Roberts, M. E. (2013). How censorship in China allows government criticism but silences collective expression. American Political Science Review, 107(2), 326-343.

$\mathrm{Li}$, J., \& Li, X. (2017). Media as a core political resource: the young feminist movements in China. Chinese Journal of Communication, 10(1), 54-71.

$\mathrm{Li}, \mathrm{X}$. (2012) A Study of the Characteristics of Women's Rights in Modern China, from the Late Qing to the May Fourth Era. Gaoxiong Shida Xuebao 2012(33): 43-59.

Lim, L. (2018, March 2). China's \#MeToo censorship bypassed through netizens' creative use of language. South China Morning Post. Available at https://www.scmp.com/magazines/post-magazine/shortreads/article/2134847/chinas-metoo-censorship-bypassed-through

Lim, M. (2013). Framing Bouazizi:'White lies', hybrid network, and collective/connective action in the 2010-11 Tunisian uprising. Journalism, 14(7), 921-941.

Liu, M. (1999). Enduring violence and staying in marriage: Stories of battered women in rural China. Violence Against Women, 5, 1469-1492.

Mackie, D. M., Devos, T., \& Smith, E. R. (2000). Intergroup emotions: Explaining offensive action tendencies in an intergroup context. Journal of Personality and Social Psychology, 79(4): 602-616.

McCarthy, J. D., \& Zald, M. N. (1977). Resource mobilization and social movements: A partial theory. American journal of sociology, 82(6), 1212-1241.

Meng, B. (2011). From steamed bun to grass mud horse: E Gao as alternative political discourse on the Chinese Internet. Global Media and Communication, 7(1), 33-51.

Mina, A. X. (2014). Batman, pandaman and the blind man: A case study in social change memes and Internet censorship in China. Journal of Visual Culture, 13(3), 359-375.

Ministry of Education (MOE) (2018). 2017 sees increase in number of Chinese students studying abroad and returning after overseas studies. Available at en.moe.gov.cn/News/Top_News/201804/t20180404_332354.html

Montada, L., \& Schneider, A. (1989). Justice and emotional reactions to the disadvantaged. Social Justice Research, 3(4): 313-334. 
Morozov, E. (2011). The net delusion: The dark side of internet freedom (1st ed.). New York, NY: Public Affairs.

Nip, J. Y. (2004). The queer sisters and its electronic bulletin board: A study of the Internet for social movement mobilization. Information, Communication \& Society, 7(1), 23-49.

Nordin, A., \& Richaud, L. (2014). Subverting official language and discourse in China? Type river crab for harmony. China information, 28(1), 47-67.

Olson, M. (1965). The logic of collective action. Cambridge. MA: Harvard University Press.

Onuch, O. (2015). EuroMaidan protests in Ukraine: Social media versus social networks. Problems of Post-Communism, 62(4), 217-235.

Pan, S. \& Huang Y. (2013). An Empirical Study of Sexual Harassment in China in the 21st Century: Discourse Intervention and Subject Construction.

Exploration and Free Views, 285(7): 58-62. Available at http://www.tsyzm.com/CN/Y2013/V1/I7/58

Papacharissi, Z. (2016) Affective publics and structures of storytelling: sentiment, events and mediality. Information, Communication \& Society, 19(3): 307-324.

Papacharissi, Z., \& de Fatima Oliveira, M. (2012). Affective news and networked publics: The rhythms of news storytelling on\# Egypt. Journal of Communication, 62(2), 266-282.

Pond, P., \& Lewis, J. (2019). Riots and Twitter: connective politics, social media and framing discourses in the digital public sphere. Information, Communication \& Society, 22(2), 213-231.

Sima, Y. (2011). Grassroots environmental activism and the Internet: Constructing a green public sphere in China. Asian Studies Review, 35(4), 477-497.

Tan, J. (2017). Digital masquerading: Feminist media activism in China. Crime, Media, Culture, 13(2), 171-186.

Van Aelst, P., \& Walgrave, S. (2002). New media, new movements? The role of the internet in shaping the 'anti-globalization'movement. Information, Communication \& Society, 5(4), 465-493.

Van Zomeren, M., \& Iyer, A. (2009). Introduction to the social and psychological dynamics of collective action. Journal of Social Issues, 65(4), 645-660.

Van Zomeren, M., Spears, R., Fischer, A. H., \& Leach, C. W. (2004). Put your money where your mouth is! Explaining collective action tendencies through group-based anger and group efficacy. Journal of personality and social psychology, 87(5), 649. 
Wang, B., \& Driscoll, C. (2019). Chinese feminists on social media: articulating different voices, building strategic alliances. Continuum, 33(1), 1-15.

Wang, Q. (2018). From "Non-governmental Organizing" to "Outer-system"Feminism and Feminist Resistance in Post-2000 China. NORA-Nordic Journal of Feminist and Gender Research, 26(4), 260-277.

Weber, I. (2011). Mobile, online and angry: the rise of China's middle-class civil society?. Critical Arts: South-north cultural and media studies, 25(1), 25-45.

Williams, S. (2015). Digital defense: Black feminists resist violence with hashtag activism. Feminist Media Studies, 15(2), 341-344.

Xinhua (2019, January 9). WeChat Al conversation system makes debut. In Xinhua News. Available at www.xinhuanet.com/english/2019-01/09/c_137731587.htm

Xu, D. (2015). Online censorship and journalists' tactics: A Chinese perspective. Journalism Practice, 9(5), 704-720.

Xu, X., Zhu, F., O'Campo, P., Koenig, M. A., Mock, V., \& Campbell, J. (2005). Prevalence of and risk factors for intimate partner violence in China. American Journal of Public Health, 95(1), 78-85.

Yang, F. (2016). Rethinking China's Internet censorship: The practice of recoding and the politics of visibility. New Media \& Society, 18(7), 1364-1381.

Yang, G. (2009). The power of the internet in China: Citizen activism online. New York, NY: Columbia University Press.

Yang, G. (2014). Internet activism \& the party-state in China. Daedalus, 143(2), 110123.

Yang, G. (2016). Narrative agency in hashtag activism: The case of\# BlackLivesMatter. Media and Communication, 4(4), 13.

Yang, R. (2015). Corruption in China's higher education: a malignant tumour. International Higher Education, (39): 17-20.

Yi, Q. \& Cheng, T. (2015). Weixin Gongzhong pingtai de xinwen chuangboxing fenxi. Chuanbo yu Banquan 2015(6): 78-82.

Zeng, J. (forthcoming, April 2020). The Third Gender in China. In Warfield, K., Abidin C., \& Cambre, C. (eds). Mediated Interfaces: The Body on Social Media. London: Bloomsbury Academic.

Zeng, J. (2019). You say \#MeToo, I say \#MiTu: China's online campaigns against sexual abuse. In Fileborn, B. \& Loney-Howes, R. (eds). \#MeToo and the politics of social change. Palgrave MacMillan. 
Zeng, J., Chan, C. H., \& Fu, K. W. (2017). How Social Media Construct "Truth" Around Crisis Events: Weibo's Rumor Management Strategies After the 2015 Tianjin Blasts. Policy \& internet, 9(3), 297-320.

Zhao, Y. (2014). Cong Weixin gongong hao kan zhimei yu xinmeiti de ronghe. Chuanmei 2014 (10): 36-38.

Zheng, Y., \& Wu, G. (2005). Information technology, public space, and collective action in China. Comparative Political Studies, 38(5), 507-536.

Zheng, Y., \& Yu, A. (2016). Affordances of social media in collective action: the case of Free Lunch for Children in China. Information Systems Journal, 26(3), 289313.

Zhou, X. (2009). The political blogosphere in China: A content analysis of the blogs regarding the dismissal of Shanghai leader Chen Liangyu. New Media \& Society, 11(6), 1003-1022.

\section{LIST OF FIGURES and CAPTIONS}

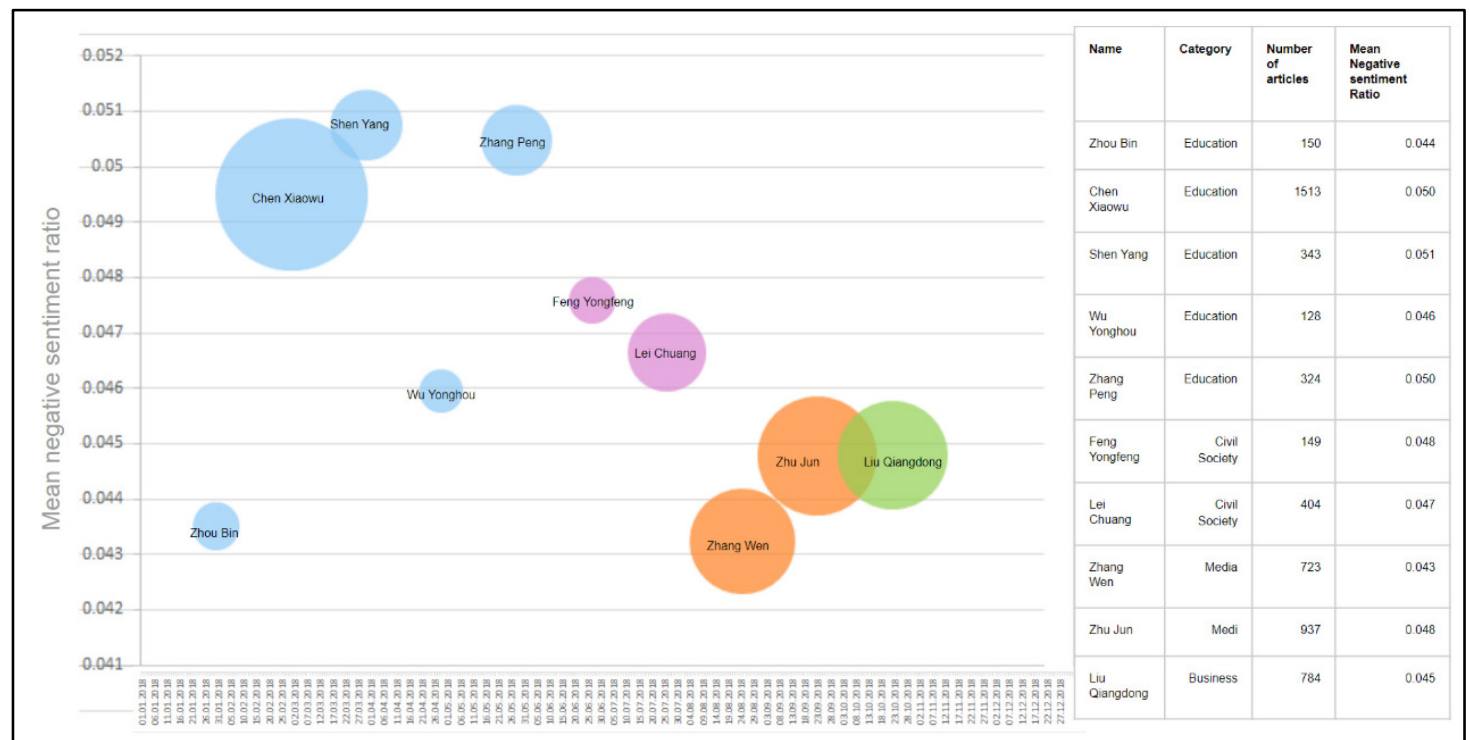

Figure 1. Scatter chart of selected allegation cases (Each dot represents a case, and is sized according to the number of articles relevant to it. Colour-coded case categories are: education, blue; media, orange; civil society, pink; and business, green.) 


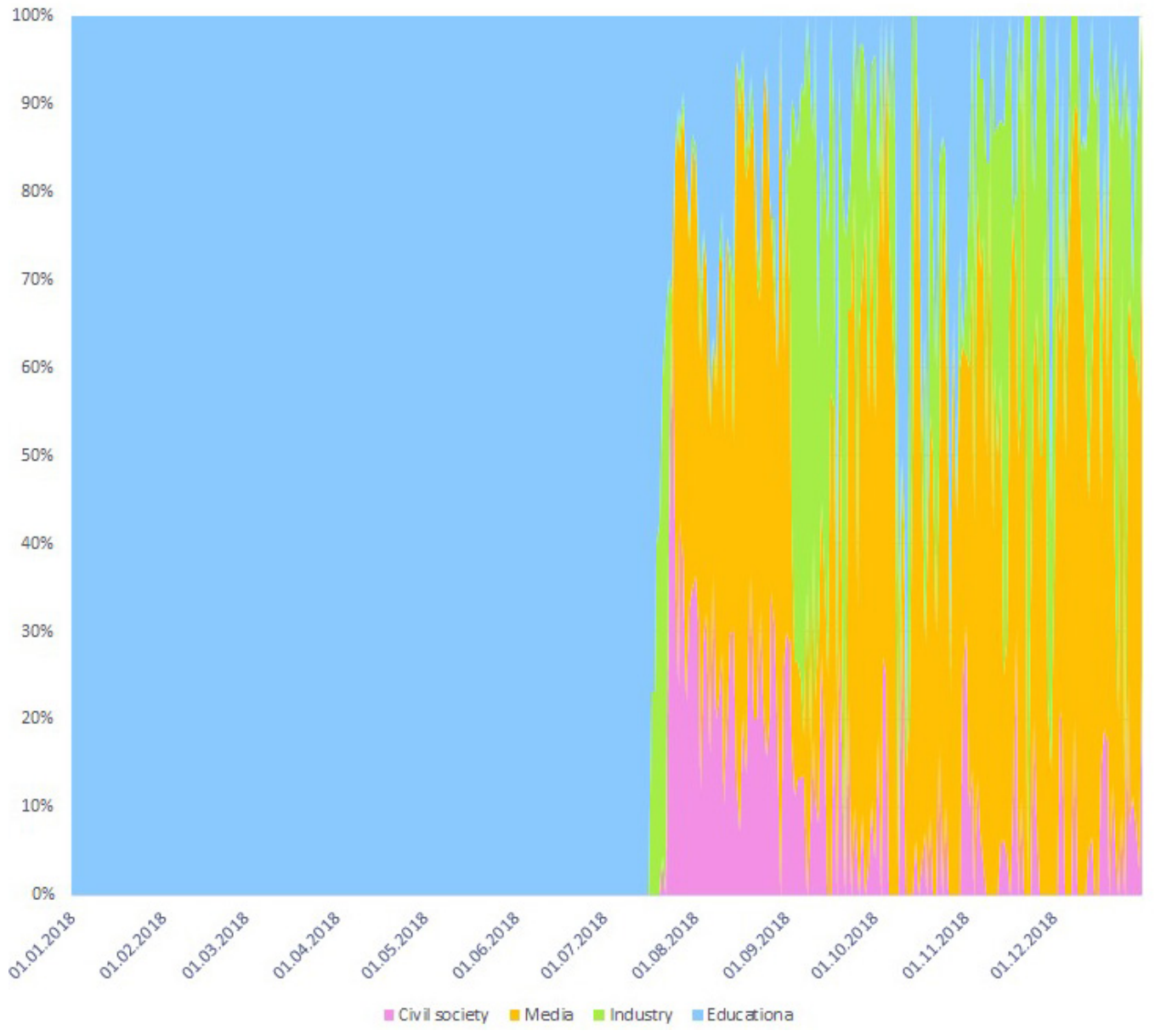

Figure 2. Time series of articles (percentage) related to sexual abuse allegations from four sectors: education (blue); media (orange); civil society (pink); and business (green) 


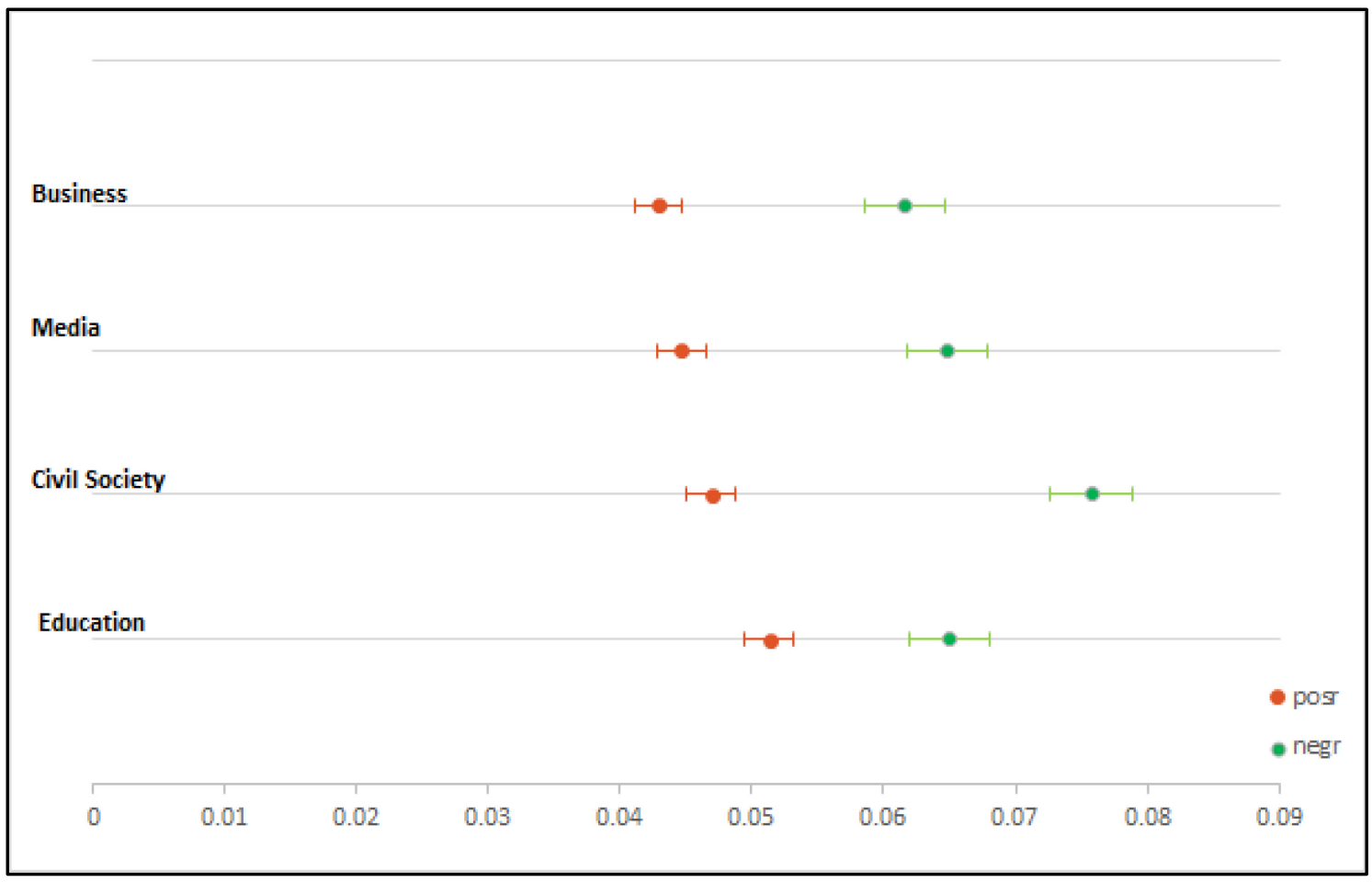

Figure 3. Mean positive sentiment ratio (posr) and mean negative sentiment ratio (negr) of articles related to allegations, organised into four sub-datasets: education, civil society, media, and business

公益, 这个本该是最纯粹最干净的领域, 接连发生如此污浊卑劣的事, 不得不让民众开始反思, 某些 所谓公益组织, 无非是抱团的利益帮派罢了。对外高谈公益道义, 其实狗苟蝇营, 唯利是图。

公益界的名人, 利用良好的社会形象, 当成了迷惑女性的蒙汗药, 但纸终究包不住火, 恶行迟早会浮出 水面。

是时候撕开某些公益名人身上的光环, 让他们露出狰狞面孔了!

让这些败类明白：没有私德，做个鸟公益！

Figure 4: screenshot of @Gongyiwangxi's original WeChat article 


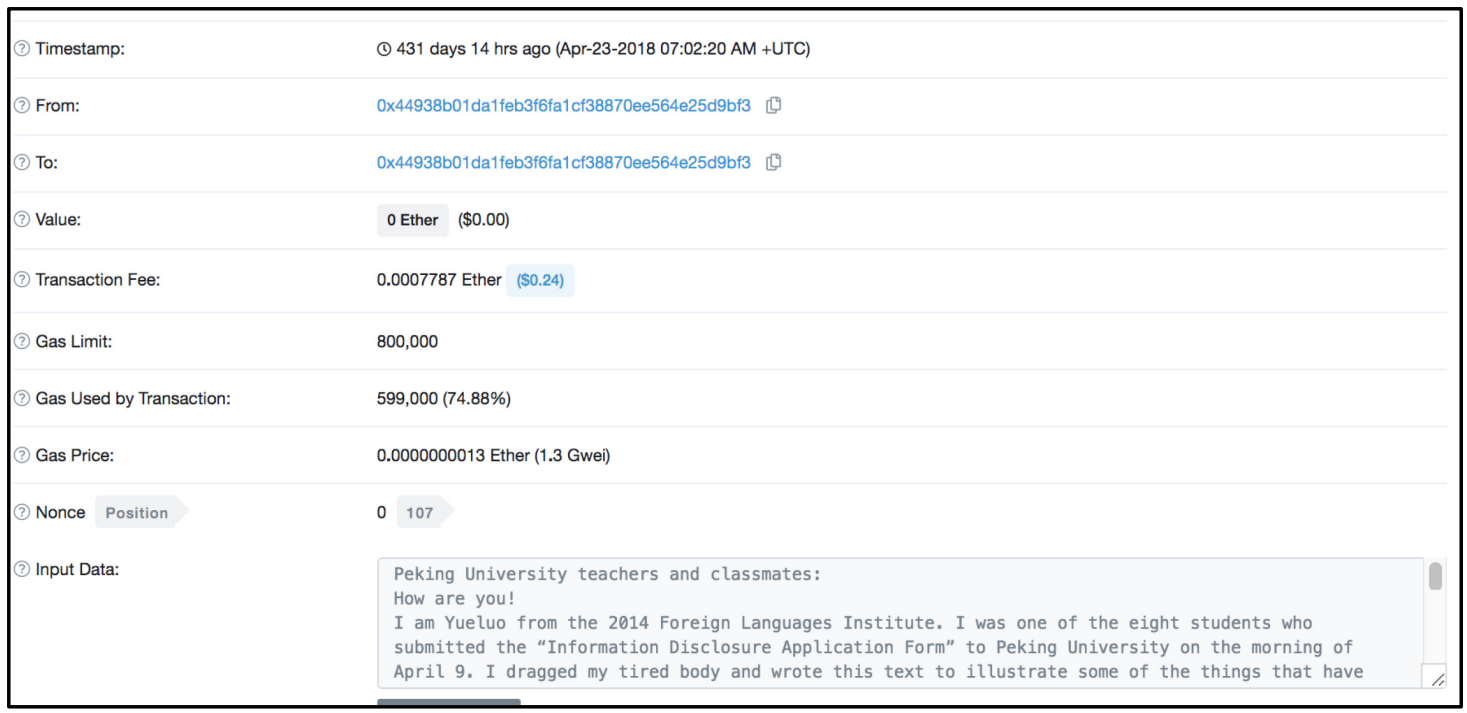

Figure 5: screenshot of the Ether transaction record with Yue Xin's open letter

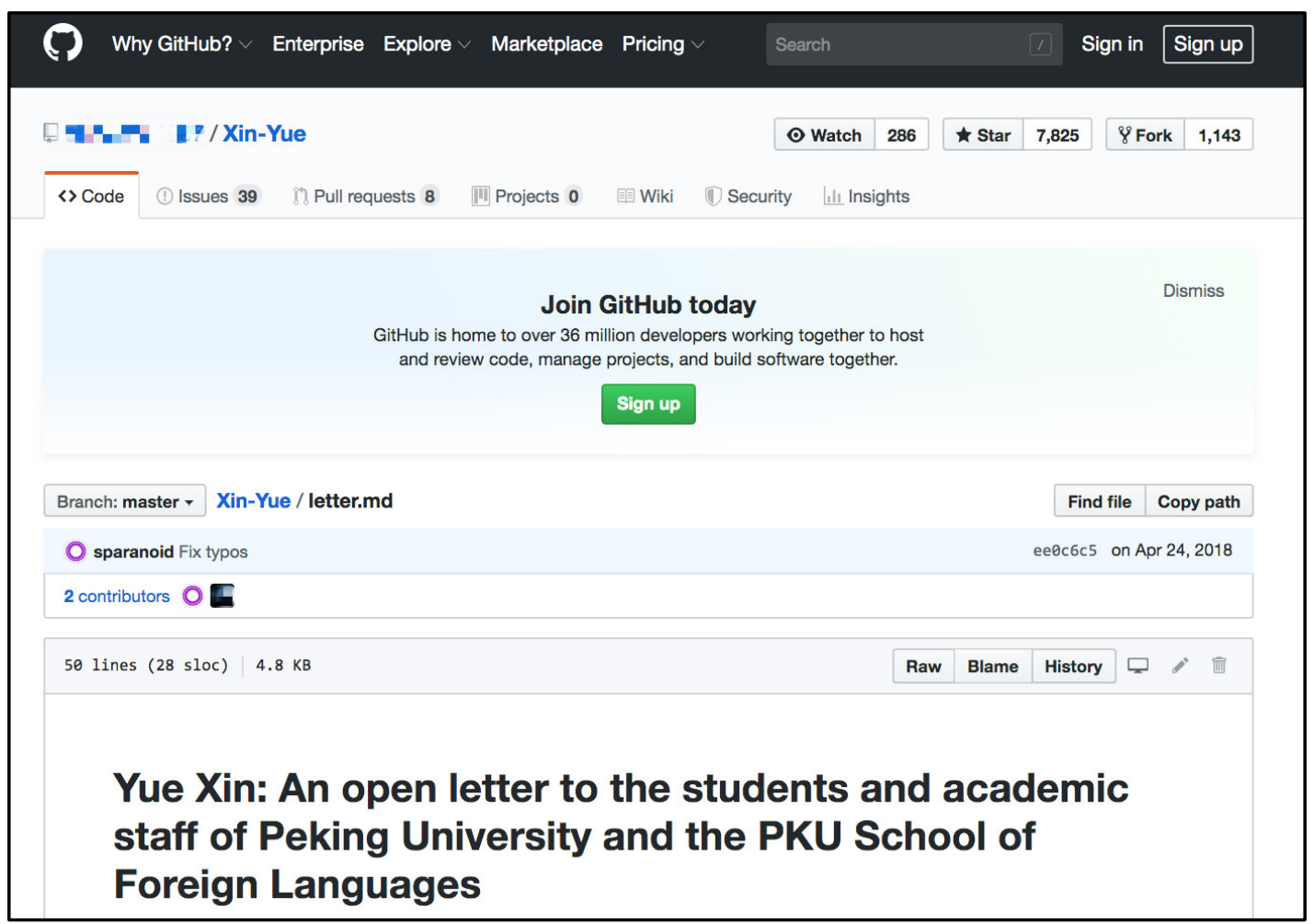

Figure 6. Screenshot of a GitHub page where YueXin's open letter is cached 


\section{LEARN CHINESE: \#METOO}

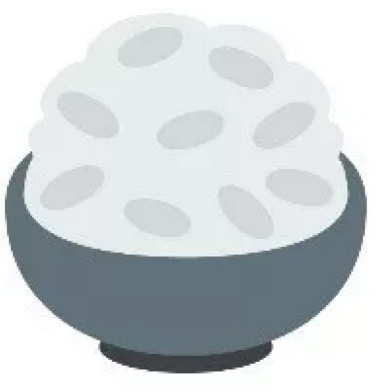

(Mi)

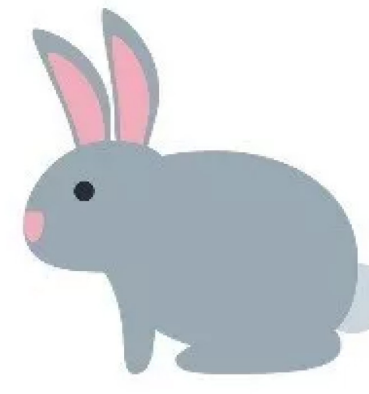

(Tu)

$$
\text { 米 }
$$

兔

No Sexual Harassment

\section{禁止性骚扰}

Figure 7. Image used by social media activists (Source: WeChat)
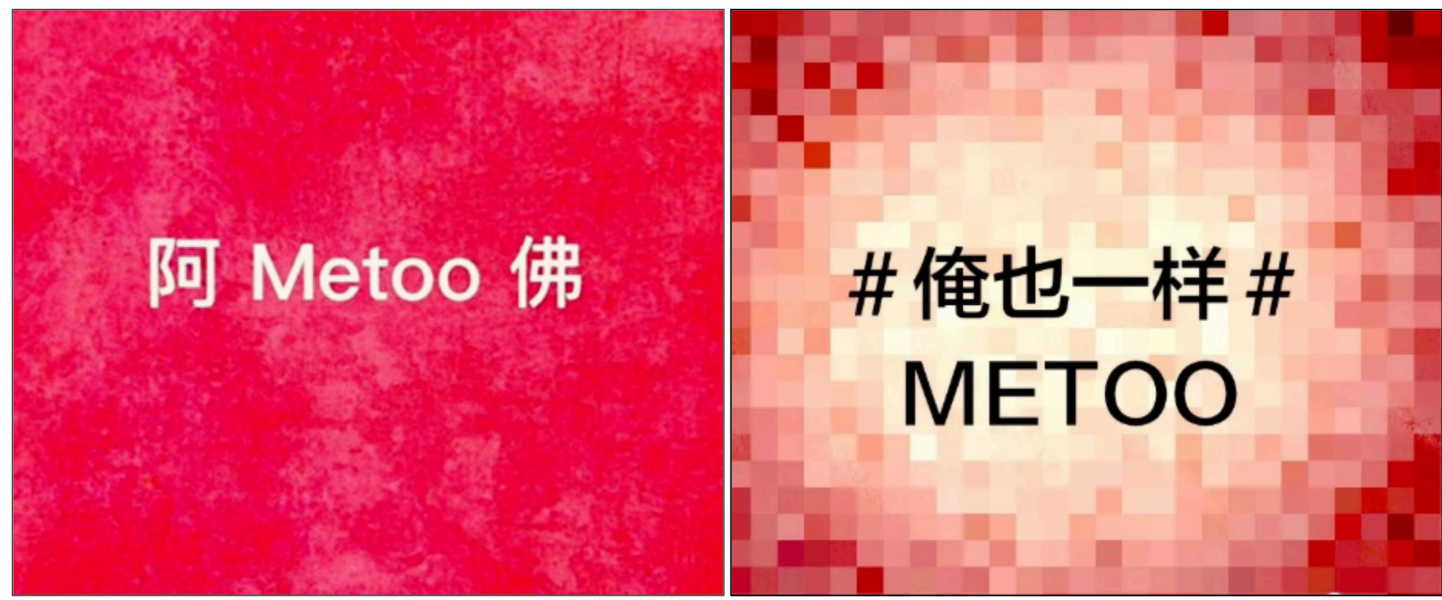

Figure 8. Screenshot of images of "a'metoo'fo" and \#MeToo in northern Chinese dialect 


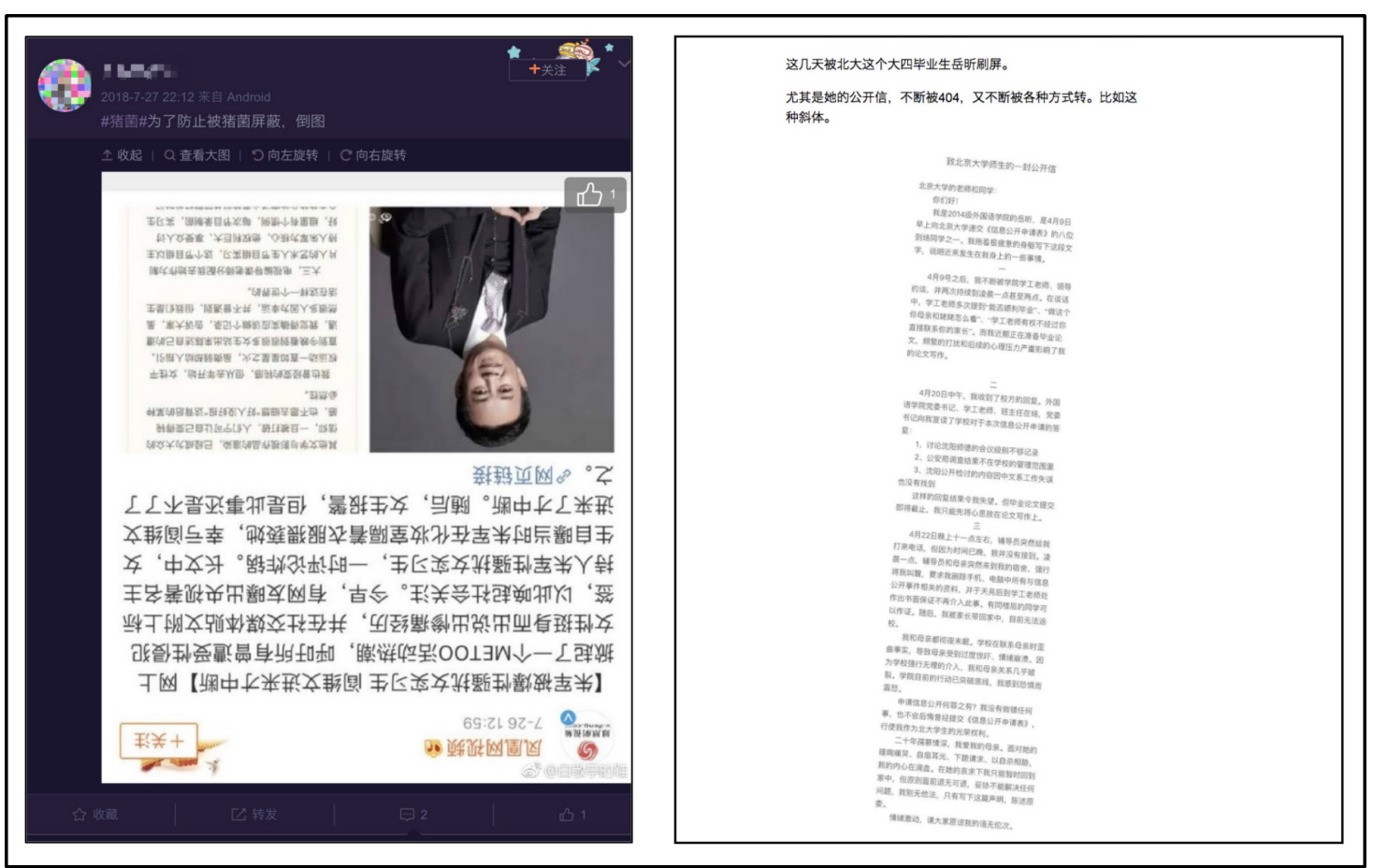

Figure 9. Examples of pictures rotated to bypass censorship 